\title{
THREATS TO AQUATIC FAUNAL DIVERSITY DUE TO SHRIMP PENAEUS MONODON POST LARVA COLLECTION IN KUAKATA SEA BEACH OF PATUAKHALI
}

\author{
M. M. Hasan, M. S. Islam*, M. M. Islam, A. Khanam and M. Akter \\ Department of Coastal and Marine Fisheries, Sylhet Agricultural \\ University, Sylhet, Bangladesh
}

\begin{abstract}
To assess the abundance of black tiger shrimp (Penaeus monodon) post larvae (PL) and to quantify the damage of different aquatic fauna during collection of shrimp PL. About 37 PL of other shrimps, 11 fin fish larvae and 31 macrozooplankton were wasted during collection of a single shrimp PL. During the survey period, around 1.55 million man days/year were estimated to be involved in shrimp PL collection activities and on average 216 million of shrimp PL were collected annually from the studied area. About 17,064 million of other shrimps, fin fishes and macrozooplankton were destroyed annually by shrimp seed collectors in Kuakata beach. Variation in water surface temperature and $\mathrm{pH}$ was not found but salinity and hardness showed great fluctuation during the study period. Water temperature, salinity and $\mathrm{pH}$ are significantly $(\mathrm{p}<0.01)$ correlated with shrimp PL abundance. Therefore, the results imply that present seed collection practice causes severe damage of other valuable aquatic fauna, which directly affect the faunal diversity, natural productivity and self recruitment pattern of mother stock.
\end{abstract}

Key words: Shrimp, fin fish, macrozooplankton, shrimp seed collectors, biodiversity

\section{INTRODUCTION}

Coastal aquaculture of Bangladesh is dominated by black tiger shrimp and giant freshwater prawn (Macrobrachium rosenbergii). Bangladesh is considered one of the most suitable countries in the world for shrimp and prawn farming because of its resources and favorable agro-climatic conditions. A sub-tropical climate and a vast area of shallow waterbodies provide a unique opportunity for shrimp and prawn production (Ahmed et al. 2008). The culture of shrimp and prawn in the coastal area is a major export earning activity for Bangladesh. This culture is ongoing in the coastal belt during the early 1980s to supply international markets and earn foreign currencies (Islam et al. 2001). The Government and private sector intensified efforts to increase export earnings from this sector.

The capture of wild PL to stock in aquaculture facilities is a critical point of shrimp farming (Paez-osuna 2001). Although hatchery produced post larvae are

*Author for correspondence: <islamms2011@yahoo.com>.

@2019 Zoological Society of Bangladesh DOI: https://doi.org/10.3329/bjz.v47i2.44338 
now available in many countries in Asia and Latin America, wild fry still provides the significant source of seed in many locations (FAO 2007). Horizontal expansion of shrimp growing area, the trend of selective stocking and inadequate supply of hatchery produced PL in need have resulted in a tremendous demand for natural shrimp PL. Farmers opine that wild post larvae to be of excellent quality than hatchery produced shrimp PL for culture. Due to high demand, low investment and profitable business of shrimp PL, it is encouraged thousands of resource poor people of the coastal area to be engaged in shrimp seed collection (Islam et al. 1999a). Wild PL collection has given employment opportunity for thousands of coastal landless and unemployed people (Islam and Wahab 2005). It has been estimated that about 2 billion shrimp fry are collected annually from wild sources (Banks 2003). With respect to freshwater prawn more than $90 \%$ of the total PL is derived from natural sources and in the case of tiger shrimp, more than $50 \%$ is derived from wild sources (Banks 2003). As a result, innumerable shrimp PL are harvested from the tidal creeks, rivers, estuaries and sea coast. Different types of nets like drag net, push net and set bag nets are mostly used in shrimp fry collection activities. The collector or other member of the family/group pick out only the targeted shrimp PL and the rest composed of other shrimp, macrozooplankton and fin fish larvae is discarded on the hot dry shore. In this way, huge number of fry of different fin fish and shell fish species are destroying everyday. Khan and Latif (1997) reported that the wild shrimp and fish stock are greatly affected due to this practice.

Wild shrimp PL collection is assumed a notorious impact on coastal biodiversity (Primavera 1998, Islam et al. 1999a and Hoq et al. 2001). It has also been reported that about 2499 other shrimp larvae, fin fish and macrozooplankton were discarded for collecting a single shrimp PL in Mongla river, Bagerhat (Ferdousi et al. 2017). In Bangladesh, up to 5000 shrimp PL may be wasted for every 100 shrimp PL captured by collectors (BOBP 1990). Around $40 \%$ of the collected seed died before stocking in culture facilities due to poor handling and transportation in Bangladesh (Brown 1997). This study explores the present status of shrimp PL and other aquatic organisms, and the loss of aquatic faunal diversity by wild $P$. monodon PL collection in Kuakata beach, Patuakhali. 


\section{MATERIAL AND METHODS}

The study area of this research covering the entire Kuakata beach of Patuakhali. It lies between latitude $21^{\circ} 52^{`} \mathrm{~N}$ and $22^{\circ} 00^{\prime} \mathrm{N}$ and longitude $90^{\circ} 08^{`} \mathrm{E}$ and $90^{\circ} 16^{\circ} \mathrm{E}$ (Fig. 1). For samples collection, three different spots in Kuakata beach of Kalapara Upazila of Bangladesh were selected.

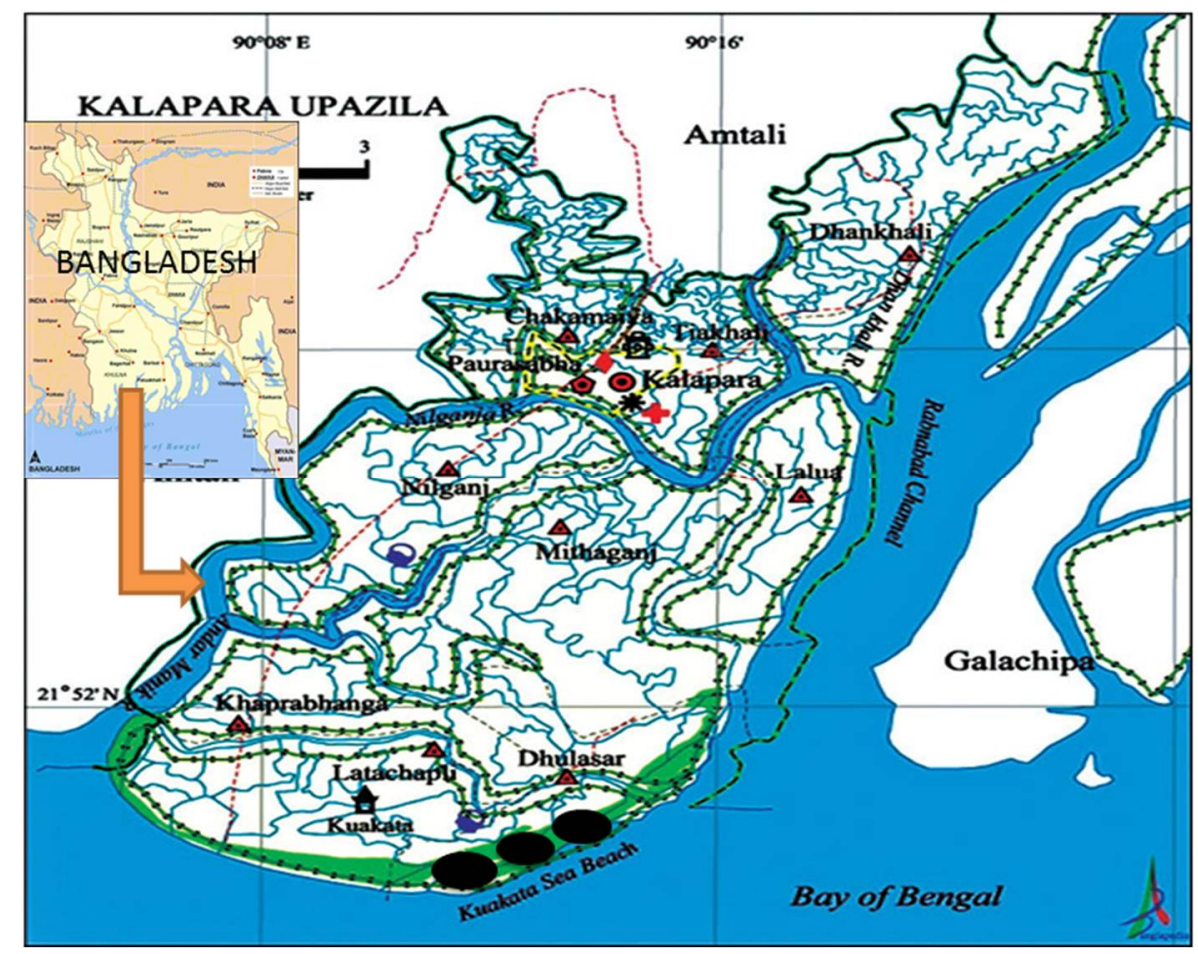

Fig. 1. Large black mark showing the study area in Kalapara Upazilla (Source: Google map).

Monthly intervals sampling was made using a rectangular drag net of nylon netting (mesh size $0.3 \mathrm{~mm})$ and bamboo split structure $(1.6 \times 0.6 \mathrm{~m})$. Sample was taken in the course of full-moon and new-moon. The net was operated in shallow water of the beach. Each hauling time was 10 minutes. Two samples were collected at the time during low and high tides. Samples were immediately stored in plastic pot and preserved in 5\% neutralized formalin after collection for sorting shrimp PL, larvae of fin fishes, shell fish and other organisms. Salinity of water of each spot was measured using a portable Refractometer (ATAGO, $\mathrm{S} /$ Mill-E). Water temperature and $\mathrm{pH}$ were estimated using an alcohol thermometer and a digital pH meter (HANNA Company, America), respectively. Total hardness of water was determined titrimetrically using a standard solution of EDTA-0.800 M and Manver 2. 
The samples collection period started from September, 2017 and were continued up to August, 2018. Samples were brought into the Water quality and biological laboratory of Department of Coastal and Marine Fisheries under Sylhet Agricultural University, Sylhet for analysis and it was performed within two weeks from the date of collection. Penaeid shrimp larvae were identified up to species level following Muthu (1978) and Motoh and Buri (1980). Macrozooplankters including other shrimp species and fin fishes were identified as major taxonomic groups following Fischer and Witchead (1974), George (1969) and Quddush and Shafi (1998). Statistical analysis was done using SPSS (Statistical Package for Social Science) version 20 and correlation was determined through $\mathrm{t}$ test.

\section{RESULTS AND DISCUSSION}

Table 1 shows the monthly abundance and distribution (individual/unit effort) of tiger shrimp, other shrimp species, fin fish and macrozooplankton in Kuakata beach. Data revealed that shrimp PL were entirely absent from July to October in all the spots while salinity was moderately lower. Larvae of shrimp were rarely available during November to February though salinity gradually increased. Generally, P. monodon PL was abundant from October to February, associated with moderate salinity (Hoq et al. 2001). This decline of shrimp PL from previous (Islam et al. 1999a) to present study is a potential threat to their future. Primavera (1998)) observed two peaks (winter and premonsoon) for penaeid recruitment and settlement at average salinity and high temperature. A similar trend was found in the present study. Zafar and Mahmood (1994) observed highest density of penaeid post larvae in July at high salinity and lowest in March in estuarine waters near Sundarbans. Shrimp PL is available year-round, but its abundance is limited when required for stocking in coastal culture ponds. On the contrary, abundance of other shrimps species was found to increase during the month of March to June and maximum was recorded in April through May and June at all the spots. There was no uniform pattern in abundance and distribution of both fin fish and zooplankton. During premonsoon period, comparatively higher amount of fin fishes and macrozooplankton were observed than the other months of the year. Similar trend was observed by Islam et al. (2015), Rahman et al. (1997) and Islam et al. (1999a).

Post larvae of shrimp were found to occupy very small portion in the total annual catch composition as $1.28,1.30$ and $1.13 \%$, respectively at three spots in Kuakata sea beach (Table 1). Islam et al. (1999a) reported the total average annual catch composition of shrimp was $2.44 \%$ at three spots in Kuakata coast,

which is higher than the present results due to wild mother stock is decreasing 
day by day for indiscriminate harvesting of shrimp PL. It is noticeable that annual catch composition of shrimp PL has been stood just half after 20 years owing to mainly anthropogenic activities. Juveniles of shrimps species other than P. monodon included Penaeus semisulcutes, P. indicus, P. merguiensis, Metapenaeus monoceros, M. brevicornis, Macrobrachium rosenbargii, M. malcolmsonii, M. lancesteri, M. villosimanus, M. mirabile, M. birmanicum, M. rude and $M$. dayanum were exerted of $47.02 \%$ in spot $1,46.11 \%$ in spot 2 and $46.28 \%$ in spot 3 of Kuakata beach, which has resemblance with the results of Islam et al. (1999a) who reported the average annual catch composition of other shrimps as 49.78\% in Kuakata.

Table 1. Monthly abundance (individual/unit effort)* of Penaeus monodon, other shrimp PL, fin fishes and other macrozooplankton of the Kuakata beach

\begin{tabular}{llll}
\hline \multirow{2}{*}{ Major groups } & \multicolumn{3}{c}{ Months } \\
\cline { 2 - 4 } & Sept. Oct. Nov. Dec. Jan. Feb. Mar. Apr. May Jun. Jul. Aug. total $\%$ \\
\hline
\end{tabular}

\begin{tabular}{lcccccccccccccc}
\hline Kuakata beach (Spot 1) & & & & & & & & & & & & \\
$P$. monodon & 0 & 0 & 3 & 2 & 1 & 2 & 3 & 2 & 2 & 2 & 0 & 0 & 17 & 1.28 \\
Other shrimps & 47 & 34 & 25 & 39 & 37 & 45 & 56 & 97 & 63 & 85 & 55 & 42 & 625 & 46.92 \\
Fin fish & 10 & 9 & 14 & 13 & 9 & 13 & 32 & 18 & 13 & 14 & 11 & 15 & 171 & 12.84 \\
Macrozooplankton & 45 & 26 & 60 & 36 & 9 & 10 & 13 & 108 & 55 & 75 & 59 & 23 & 519 & 38.96 \\
Total & 102 & 69 & 102 & 90 & 56 & 70 & 104 & 225 & 133 & 176 & 125 & 80 & 1332 & 100.00 \\
Kuakata beach (Spot 2) & & & & & & & & & & & & & \\
P. monodon & 0 & 0 & 4 & 2 & 2 & 3 & 2 & 2 & 1 & 2 & 0 & 0 & 18 & 1.31 \\
Other shrimps & 48 & 36 & 25 & 40 & 39 & 47 & 57 & 92 & 65 & 86 & 56 & 43 & 634 & 46.11 \\
Fin fish & 11 & 10 & 15 & 14 & 10 & 15 & 34 & 19 & 14 & 15 & 12 & 17 & 186 & 13.53 \\
Macrozooplankton & 47 & 28 & 63 & 38 & 10 & 10 & 14 & 107 & 57 & 77 & 61 & 25 & 537 & 39.05 \\
Total & 106 & 74 & 107 & 94 & 61 & 75 & 107 & 220 & 137 & 180 & 129 & 85 & 1375 & 100.00 \\
Kuakata beach (Spot 3) & & & & & & & & & & & & & \\
P. monodon & 0 & 0 & 3 & 1 & 3 & 2 & 1 & 2 & 1 & 2 & 0 & 0 & 15 & 1.14 \\
Other shrimps & 44 & 33 & 23 & 37 & 36 & 44 & 55 & 94 & 62 & 83 & 59 & 40 & 610 & 46.28 \\
Fin fish & 11 & 10 & 13 & 13 & 9 & 12 & 30 & 16 & 14 & 12 & 12 & 26 & 178 & 13.51 \\
Macrozooplankton & 44 & 24 & 58 & 37 & 10 & 9 & 16 & 110 & 54 & 73 & 58 & 22 & 515 & 39.07 \\
Total & 99 & 67 & 97 & 88 & 58 & 67 & 102 & 222 & 131 & 170 & 129 & 88 & 1318 & 100.00 \\
\hline
\end{tabular}

*Operating a drag net $(1.6 \times 0.6 \mathrm{~m})$ for about 10 minutes taken as a unit effort.

Larvae of fin fish like Liza parsia, Polynemus paradiseus, Polydactylus indicus, Rhinomugil corsula, Otolithoides pama, Labotes surinamensis, Pampus chinensis, Gudusia chapra, Mystus spp., Harpadon nehereus, Glossogobius spp., Mastacembelus armatus, Puntius spp., Pangasius pangasius, Setipinia phasa, Trichiurus haumela and Pomadasys hasta shared of 12.83, 13.52 and 13.50\% of total catch in spot 1, 2 and 3, respectively. Islam et al. (1999a) stated the larvae of fin fishes at three spots were $8.07 \%$ in Kuakata. Islam et al. (1999b) also 
reported the average yearly catch composition of fin fish larvae in the Meghna river at Bhola was $11.45 \%$. However, it is clear from the above studies that destruction of fin fish larvae is increasing year after year for human activities in coastal waters.

Macrozooplankton (Acetes sp., mysids, isopods, copepod, alima, crab larvae, etc) showed higher density of 38.96, 39.05 and $39.07 \%$, respectively at three spots in Kuakata beach. Islam et al. (1999a) and Islam et al. (1999b) stated the total annual average catch composition of macrozooplankton was $39.71 \%$ in Kuakata and $60.41 \%$ in the lower Meghna river (Bhola). Mahmood (1990) reported higher density of zooplankton (98.30\%) was found in Chakaria Sundarbans followed by Satkhira (97.72\%) and Khepupara (97.53\%). Moreover, other shrimp and fin fishes shared only about $2 \%$ of the zooplankton community and shrimp post larvae alone contributed a very small quantity to the total annual catch (0.7\% in Chakaria and Khepupara, and $1.2 \%$ in Satkhira). Islam et al. (1999a) reported zooplankton in Andermanik river of Patuakhali (53.51\%) and Ichamati river (93.19\%) as well as Kholpatula river (96.56\%) of Satkhira district that was also higher than fin fishes and other shrimps. Other shrimps and fin fishes secured 40.60 and 5.28\%, respectively in Andermanik. But these were 5.18 and $1.57 \%$ in the Ichamati and 9.84 and $0.92 \%$ in the Kholpatula, respectively. PL of shrimp alone scored the minimal number in both the Andermanik river $(0.61 \%)$ and Satkhira $(0.06$ and $0.05 \%)$ region, due to these waterbodies are far away from the Bay.

The catch composition and the extent of damage caused to macrozooplankton and other aquatic organisms as a result of mercilessly harvesting of shrimp PL have been displayed in Table 2. It was found that on average in the total relative abundance, shrimp PL contributed only $1.27 \%$, other shrimp species $46.42 \%$, fin fishes $13.26 \%$ and macrozooplankton $39.05 \%$. The results of this study indicate that shrimp seed collectors killed about 37 other shrimp species, 11 fin fishes and 31 macrozooplankton for catching a single post larva of shrimp. Islam et al. (1999a) reported 32 other shrimp spp., 5 fin fishes and 33 macrozooplankton were destroyed for catching only one post larva of shrimp in the estuaries and beach of Patuakhali.

According to Mahmood (1990) for catching only one PL of shrimp, 14 other shrimp spp., 21 fin fishes and 1631 zooplanktons were killed in the Chakaria Sundarbans, Satkhira and Khepupara estuaries. The variations in the zooplankton population with the present findings might be due to difference in mesh size of the collection net. Mahmood (1990) used a rectangular nylon net 
with smaller mesh size $(0.5 \mathrm{~mm})$. The mesh size of the net used in the present study was $0.3 \mathrm{~mm}$ which is similar to that used by seed collectors. For this reason, smaller zooplankton and other species could not escape through smaller mesh $(0.3 \mathrm{~mm})$ of net used in this study. Rahman et al. (1997) also reported death of 58 other shrimp, fin fish and macrozooplankton for the collection of each shrimp PL. The tremendous loss of valuable different aquatic organisms was also reported by Islam et al. (1999b) and BOBP (1992). In addition, this practice also causes death of huge number of shrimp PL due to there is every possibility of destructive different appendages of PL and also become stress during collection, sorting, storing and transportation, which finally caused their death.

Table 2. Average catch composition (\%) of Penaeus monodon PL, other shrimp species, fin fishes and macrozooplankton in the Kuakata beach

\begin{tabular}{lccc}
\hline Major taxa & $\begin{array}{c}\text { Catch/unit effort } \\
\text { (No.) }\end{array}$ & $\begin{array}{c}\text { Relative abundance } \\
(\%)\end{array}$ & $\begin{array}{c}\text { No. of other species damaged } \\
\text { for each shrimp PL collection }\end{array}$ \\
\hline P. monodon & 17 & 1.27 & -- \\
Other shrimps & 623 & 46.42 & 37 \\
Fin fish & 178 & 13.26 & 11 \\
Macrozooplankton & 524 & 39.05 & 31 \\
Total & 1342 & 100.00 & 79 \\
\hline
\end{tabular}

Observation on the number of seed collectors/km, length of the sea beach, number of boat and hour of appointment revealed that 1.55 million mandays/year were involved in shrimp seed collection activities in Kuakata beach. Islam et al. (1999a) reported 2.65 million man days/year were involved in shrimp seed collection activities in Patuakhali Kuakata beach. It is remarkable that number of seed collectors decreased with decreases the availability of shrimp PL in surveyed area. It was observed that about 216 million of shrimp PL were collected in Kuakata beach during this study from September, 2017 to August, 2018. It was also assessed that 17,064 million of other shrimp species, fin fishes and macrozooplankton were wasted annually by shrimp seed collectors in the beach. Islam et al. (1999a) reported about 339 million of shrimp PL were collected in the water of Patuakhali estuaries in 1996 and 23730 million of other shrimp species, fin fish and macrozooplankton were destroyed by PL collectors, which is alarming for diversity of coastal aquatic fauna. The severe impact of shrimp seed collection activities drastically reduced the availability of shrimp PL from 2,000 shrimp fry/net/day (Funegaard 1986) to only 200 - 50 fry/net/day (Islam et al. 2015) in Satkhira and Bagerhat districts. 
Monthly mean values of water temperature, salinity and $\mathrm{pH}$ are shown in Fig. 2. There was no significant variation in water temperature but a wide fluctuation in salinity was found at all the spots. Maximum water temperature $\left(31.5^{\circ} \mathrm{C}\right)$ was recorded in May and minimum $\left(21.0^{\circ} \mathrm{C}\right)$ in January, which is similar with the observation made by Islam et al. (1999a), who recorded the highest temperature $32.7^{\circ} \mathrm{C}$ in May and the lowest temperature $21.5^{\circ} \mathrm{C}$ in January in Kuakata beach. Water salinity varied from 1.0 - $18.5 \mathrm{ppt}$, which is coincided with the findings of Islam et al. (1999a), who reported salinity as 1.0 $18.0 \mathrm{ppt}$ in tidal water of Kuakata beach. Water $\mathrm{pH}$ ranged from 6.8 - 8.3. Highest (8.3) $\mathrm{pH}$ was recorded in February and the lowest (6.8) in September. This observation was found to consistent with the findings of Islam et al. (1999a), who reported $\mathrm{pH}$ of $6.7-8.2$ in Kuakata beach. Total hardness varied from 688.3 - $1965.0 \mathrm{mg} / \mathrm{l}$ in studied area was found to support the findings of Sarkar (2004), who reported hardness values of 630.0 - $1640.0 \mathrm{mg} / \mathrm{l}$ in Sagar Island (India).

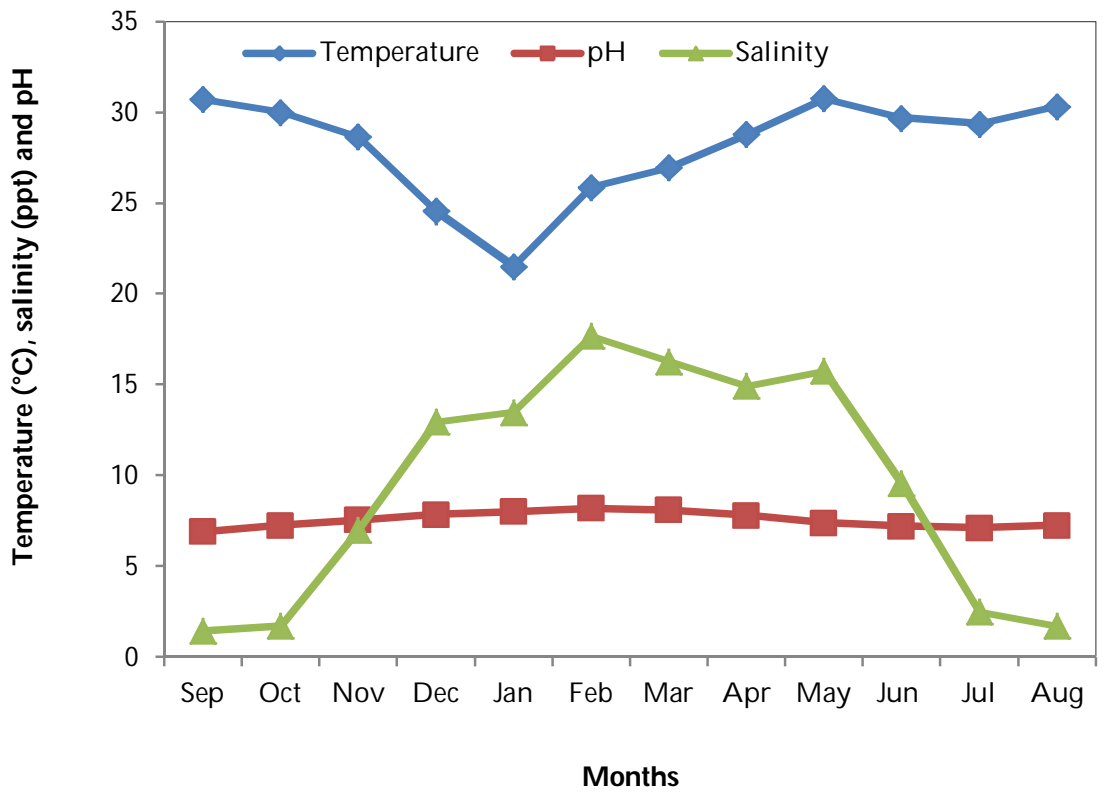

Fig. 2. Monthly fluctuation of water temperature $\left({ }^{\circ} \mathrm{C}\right)$, salinity (ppt) and $\mathrm{pH}$ in the Kuakata beach.

There was direct relationship of water temperature, salinity, $\mathrm{pH}$ and hardness with $P$. monodon PL abundance. Temperature, $\mathrm{pH}$ and salinity of sea beach water were significantly correlated with shrimp PL abundance (Table 3). The correlation study indicated that the post larvae availability was showed negative response i.e. with rising temperature the PL availability decreased. The $\mathrm{pH}$ is important for determining the availability of PL in the sea beach. Result 
showed that the increased $\mathrm{pH}$ focused the increase of PL availability. Moreover, increased salinity also showed the increase number of PL (Table 3). Hoq et al. (2001) also found the similar scenario in the tidal river systems of south-western region of Bangladesh. Salinity had been found to determine the recruitment of shrimp/prawn populations (Easo and Mathew 1989) and at moderate rainfall extended the nursery area (Garcia and Le Reste 1981). Results of this study indicated that the recruitment of other shrimps, fin fishes and macrozooplankton community of the food chain will severely decline within the next few years as the consequence of extensive shrimp PL collection. The recruitment of shrimp in the deep sea is directly dependent on the survival of these juveniles in the coastal waters. If these juveniles are captured, this will have negatively impact on the adult population of targeted shrimp and other aquatic organisms. This scenario is also true in case of fin fish larvae which are indiscriminately damaged with the targeted shrimp PL, with fatal effects on artisanal and commercial fisheries in the near future.

Table 3. The relationship of shrimp PL availability with temperature, pH, salinity and hardness in the Kuakata beach

\begin{tabular}{lc}
\hline Parameters & $\mathrm{r}$ value \\
\hline PL vs temperature & $-0.432^{* *}$ \\
PL vs pH & $0.615^{* *}$ \\
PL vs salinity & $0.648^{* *}$ \\
\hline
\end{tabular}

**Significant at $0.01 \%$ level.

\section{CONCLUSION}

It is apparent that many shrimp species and other aquatic organisms are at risk due to overfishing and other anthropogenic activities. On the other hand, fishing efforts has an increasing trend. Initiatives for shrimp PL conservation so far taken, seems to be not enough for sustainable abundance of shrimp PL. This is due to huge number of fry collectors with numerous fishing nets engaged in shrimp PL harvesting. However, it could be concluded that for the sustainable availability of shrimp PL, fishing effort to be reduced in addition to strict regulation on the mesh size of nets and release of unwanted species back to the water should be ensured through concerned authority. Destruction of valuable organisms with targeted shrimp PL should be broadcast through mass media. Only conscious coastal people should be allowed to catch shrimp PL with legal and appropriate crafts and gears in a particular area and in particular months of a year. 


\section{LITERATURE CITED}

AHMED, N., DEMAINE, H. and MUIR, J. F. 2008. Freshwater prawn farming in Bangladesh: history, present status and future prospects. Aquac. Res. 39(8): 806-819.

BANKS, R. 2003. Brackish and Marine Water Aquaculture. Report on Fisheries Sector Review and Future Development. Department of Fisheries, Matshya Bhaban, Dhaka 1000, Bangladesh. pp. 123.

BAY of BENGAL PROGRAM (BOBP). 1992. The estuarine set bag net fisheries of Bangladesh. Bay of Bengal News, Issue No. 47, Madras, India. pp. 1-10.

BOBP (Bay of Bengal). 1990. Shrimp seed collectors of Bangladesh. BOBP/WP/63, FAO: 37pp.

BROWN, B.E. 1997. Integrated Coastal Management: South Asia. Department of Marine Science and Coastal Management. Chapter 4. University of Newcastle, UK.

EASO, S. AND MATHEW, K.J. 1989. Seasonal variations in the abundance of penaeid prawn seed in relation to environmental parameters in the seed grounds of Cochin backwaters. Ind. J. Fish. 36: $125-132$.

FERDOUSY, J., ISLAM, M.S. and BEGUM, N. 2017. Abundance of shrimp (Penaeus monodon) post larvae (PL) and to quantify the damage of different aquatic fauna during shrimp PL collection in Mongla tidal river (Rampal), Bagerhat. J. Sci. Res. 9(1): 87-95.

FISCHER, W. and WITCHEAD, P.J.P. (Eds). 1974. FAO species identification sheets for fishery purposes. Eastern Indian Ocean Fishing Area 57 and Western Central Pacific Area 71. Rome, FAO, Pag-Var. 1-4: 99-126.

FOOD and AGRICULTURE ORGANIZATION (FAO). 2007. Marine shrimp farming and genetic resources. www.fao.org/fi/website/

FUNEGAARD, P. 1986. Shrimp seed any to sell? Come to Satkhira, Bangladesh. Bay of Bengal News 22: 2-6.

GARCIA, S. AND L. LE RESTE. 1981. Life cycles dynamics, exploitation and management of coastal penaeid shrimp stocks. FAO Fish. Tech. Pap. 302: 215.

GEORGE, M.J. 1969. Prawn fisheries in India, II. Systematics-taxonomic considerations and general distribution. Bulletin Cent. Mar. Fish. Res. Ins. 14: 5-48.

HOQ, M.E., ISLAM, M.N., KAMAL, M. and WAHAB, M.A. 2001. Abundance and seasonal distribution of Penaeus monodon post larvae in the Sundarbans mangrove, Bangladesh. Hydrob. 457 (1-3): 97-104.

ISLAM, M.S. and AHMAD, S.U. 2001. By-catch mortality during collection of Penaeus monodon (FAB) post-larvae from the rivers of Khulna, Bangladesh. J. Nat. Sci. Found. of Sri Lanka 29(3-4): 107115.

ISLAM, M.S. and WAHAB, M.A. 2005. A review on the present status and management of mangrove wetland habitat resources in Bangladesh with emphasis on mangrove fisheries and aquaculture. In Aquat. biod. II: 165-190. Springer, Dordrecht.

ISLAM, M.S., ISLAM, M.M. and AHMED, S.U. 1999a. Abundance of Penaeus monodon post larvae and effect of post larvae collection on the biodiversity in estuaries of Patuakhali, Bangladesh. Bangladesh J. Fish. 22(2): 35-40.

ISLAM, M.S., ISLAM, M.M. and AHMED, S.U. 1999b. Observation on the damage of shell and fin-fish larvae during collection of shrimp fry (Penaeus monodon) in the estuaries of Bhola district, Bangladesh. Pakistan J. Biol. Sci. 2(4): 1096-1099.

ISLAM, M.S., RAHMAN, M.M., AHMED, K.K.U., HOSSAIN, M.M., BARMAN, P.P. and ISLAM, M.J. 2015. Loss of aquatic fauna during collection of Penaeus monodon post larvae in tidal water of Mongla river, Bagerhat. J. Asiat. Soc. Bangladesh, Sci. 41(1): 105-113. 
KHAN, M.G. and LATIF, M.A. 1997. Potentials, constraints and strategies for conservation and management of open brackishwater and marine fishery resources. In National Workshop on Fisheries Resources Development and Management in Bangladesh, Dhaka, Bangladesh. 52pp.

MAHMOOD, N. 1990. An assessment of the quantum of damage caused to the zooplankton while fishing bagda shrimp Penaeus monodon fry in Bangladesh estuaries. In Proceedings of "7th National Zoological Conference” Dhaka, Bangladesh. pp. 87-93.

MOTOH, H. and BURi, P. 1980. Identification of the postlarvae Penaeus (Crustacea, Decapoda, Penaeidae) appearing along shore waters. Aquaculture Dept. SEAFDEC, Trigbaun, Iliolio, Philippines, Res. Rep. 4(2): 15-19.

MUTHU, M.S. 1978. Larval development: Specific identity of penaeid postlarvae found in brackishwater areas in coastal aquaculture. In: Marine Prawn Culture, Part-1: Larval development of Indian penaeid prawns (ed. KNK Kartha). CMFRI Bulletin 28: 86-90.

PAEZ-OSUNA, F. 2001. The environmental impact of shrimp aquaculture: Causes, effects and mitigation alternatives. Envir. Manag. 28(1):131-140

PRIMAVERA, J.H. 1998. Tropical shrimp farming and its sustainability. In: Tropical mariculture, Academic Press. pp. 257-289.

QUDDUSH, M.M.A and SHAFI, M. 1998. Bangaposagarer Matshya Sampad (Fisheries Resources of Bay of Bengal). Bangla Academy, Dhaka, Bangladesh. pp. 1-476.

RAHMAN, S.L., ISLAM, M.M., HOQ, M.E., HALDAR, G.C. and AHMED, S.U. 1997. A study on damage caused to crustacean and finfish larvae during collection of Penaeus monodon (Fab.) postlarvae in the estuaries of Barguna, Bangladesh. Bangladesh J. Fish. Res. 1(1): 41-46.

SARKAR, A.K. 2004. Evaluation of coastal aquatic biodiversity loss during wild shrimp (Penaeus monodon) seed collection through non-selective gears (Doctoral dissertation, Kolkata). pp. 375.

ZAFAR, M. and MAHMOOD, N. 1994. Occurrence and abundance of penaeid post larvae of the genera Penaeus, Matapenaeus and Parapenaeopsis in the estuarine waters of Satkhira, Bangladesh. Chittagong Univ. Studies (II): Sci. 18: 39-45. 